\title{
HEDGER BEHAVIOUR AND ITS IMPACT ON ORDER FLOW AND EXCHANGE RATE ON FOREIGN EXCHANGE MARKETS ${ }^{1}$
}

DOI: 10.18267/j.aop.489

\section{Lubomír Skoupil*}

\begin{abstract}
The paper introduces the author's original model which describes the main behavioural traits of the foreign exchange hedger who is trying to minimise her FX market risk exposure and secure foreign currency liquidity, in order to be able to settle her liabilities in a timely manner. This behaviour is then analysed in the context of several exogenous shocks to prices and exchange rates and implications of how order flow and exchange rates react to this behaviour are drawn based on the theoretical framework. In Chapter 2, the conclusions on expected patterns in exchange rate evolution reached in the theoretical part are tested using the fuzzy clustering technique. The hypotheses reached in the theoretical section were partially supported by the empirical analysis: some of the expected patterns were revealed by the data during shock periods of prices of Brent Oil, Dow Jones Industrial Index, Standard and Poor's 500 and four currency pairs (EURUSD, USDJPY, USDCAD, EURCZK).
\end{abstract}

Key words: exchange rate, hedging, order flow, fuzzy clustering JEL Classification: F31, F37

\section{Introduction}

As traditional macroeconomic models have problems explaining both the level and the volatility of foreign exchange rates, recent research has put an emphasis on building from microeconomic foundations. In fact, the number of articles dealing with the relation between order flow and exchange rate or macroeconomic news in the short-term is growing every year, as this fresh approach seems to be able to help explain a great deal of puzzles in international finance. For the purposes of this paper, order flow will be defined as "the net of buyer-initiated and seller-initiated orders; it is a measure of net buying pressure" [Evans \& Lyons, 2002, pp. 171], where the "initiator" role is played

* Vysoká škola ekonomická v Praze, Fakulta financí a účetnictví (email: xskol12@vse.cz).

1 This paper has been developed with the financial support of the University of Economics, Prague, IGA Grant no. 5/2014 ("Financial and Economic Cycle"), which the author gratefully acknowledges. 
by the non-quoting entity. This paper assumes that the hedger is never the quoting entity as she is motivated primarily not by the achieved price, but by the volume (that is by purchasing foreign currency liquidity or getting rid of foreign currency exposure) once entering the transaction for hedging purposes. For this reason it is assumed that if the hedger buys foreign currency, she creates positive order flow and vice versa.

Evans \& Lyons [2002] show they are able to predict approximately fifty percent of daily exchange rate changes using order flow data obtained from "Reuters Dealing 2000-1" between 1 May and 31 August 1996. Rime; Sarno \& Sojli [2007, pp. 5] explain the good predictive power of order flow by seeing it as a "vehicle for aggregating both differences in interpretation of news in real time and changes in heterogeneous expectations about the future state of the economy", which corresponds with the conclusions of Engel \& West [2005]. Order flow would thus be a variable carrying a new type of information and forming the demand and supply of currencies (and therefore their relative prices) directly from microeconomic roots.

The problem with order flow is the fact that foreign exchange is generally traded over the counter and the data on volumes and prices traded and bid/asked are not centralised and broadly available. The platforms via which most of the volume is dealt provide only samples of data and even these are seldom provided due to confidentiality matters. Because order flow cannot be directly observed on a daily basis for all traded foreign exchange pairs, it has to be estimated. For example, Rime; Sarno \& Sojli [2007] found that there is a strong link between published macroeconomic news and order flow, and they see order flow as a source of new information for market participants. This paper attempts to take a detailed look at the foreign exchange market through FX hedger optics and to arrive at a conclusion on how order flow, and especially exchange rate, is affected by hedging responses to various conditions. While there are recently emerging papers which use high-frequency commodity data to explain development of foreign exchange rates, most of them are of a purely technical, econometric nature, lacking a theoretical economic frame [for example, Ferraro; Rogoff \& Rossi, 2011]. This paper builds on the microstructure foundation by analysing the motivation behind hedgers' actions on FX markets and creates hypotheses on this theoretical background.

The structure of the paper is as follows: Chapter 1 introduces the methodological framework of the theoretical model created by the author and the framework for empirical analysis: Section 1.1 describes and models the main characteristics of hedger behaviour, Section 1.2 continues with an analysis of how various exogenous shocks affect hedger's behaviour under the model described in 1.1 and how this behaviour affects order flow and exchange rate of the foreign currency. Sections 1.3 and 1.4 describe the data used and the model designed for empirical validation respectively. Chapter 2 presents the findings gained from an empirical analysis based on the fuzzy clustering econometric approach. Chapter 3 concludes. 


\section{Theoretical and empirical methodology and data used}

\subsection{Hedger behaviour: main traits}

Hedging will be defined in this paper solely at the level of transaction foreign exchange exposure to market risk. Hedging activity is defined here as managing market risk (in this case, FX risk) in a way that both the risk and the costs caused by the hedging are in an approximate balance (in other words, the hedger watches her exposure and is actively keeping it within limits based on costs connected to hedging while maintaining her main business activity). This article abstracts from managing any form of interest rate risk. The typical hedger's main business activity lies apart from foreign exchange trading: because the hedger does not have sufficient information to be persistently profitable from FX operation, she tries to minimise her exposure (volatility of profit and loss) to FX market risk while maintaining the necessary part of main business activity denominated in foreign currencies. In the case of a multicurrency portfolio, this translates into minimising the standard deviation of expected profit from a portfolio consisting only of foreign currency cash available at the time $t$ and of future foreign currency cash flows. In case only one foreign currency is present in the portfolio, this can be simplified into minimising the sum of expected positive and negative cash flows in the foreign currency $C F_{t}$ discounted by the current foreign currency effective interest rate for the relevant point in time $t+x I R^{F}{ }_{t+x}$ :

$$
C F_{t}=\sum_{x=0}^{\infty} \frac{E_{t}\left(P C F_{t+x}\right)-E_{t}\left(N C F_{t+x}\right)}{1+I R_{t+x}^{F}} .
$$

The currently expected positive and negative cash flows in foreign currency $E_{t}$ $\left(P C F_{t+x}\right)$ and $E_{t}\left(N C F_{t+x}\right)$ consist of fulfilling of contracts that are already concluded at a fixed price $P_{F i x}$ in a volume $Q_{F i x}$ and contracts that are not concluded (or not even in the process of negotiation) yet, but are expected to happen based on the information available to the hedger at the time t for an expected price $E_{t}\left(P_{\text {Float }}\right)$ in an expected volume $Q_{\text {Float }}$. All prices $P$ are denominated in the currency relevant for the asset or cash flow. $Q^{A}, P^{A}$ stand for quantities and prices coming out of assets held by the hedger, $Q^{L}$ and $P^{L}$ signify the same for cash flows connected with the liabilities side of the hedger's balance sheet: for example, for an EUR-based hedger, the expected need for purchasing 5000metric tons of coal in June 2015, while June 2015 coal contract trades at a price of $75 \mathrm{USD} / \mathrm{mt}$, would be captured in the model as $Q_{\text {Float }}^{L}=5000, E_{t}\left(P_{\text {Float }}^{L}\right)=75$. In case the hedger already covered this need yesterday on the OTC coal market at a price of $74 \mathrm{USD} / \mathrm{mt}$, this would be captured under $Q_{F i x}^{L}=5000$ and $P_{F i x}^{L}=74$.

$$
\begin{aligned}
& E_{t}\left(P C F_{t+x}\right)=\sum Q_{F i x ; t+x}^{A} * P_{F i x ; t+x}^{A}+\sum Q_{F l o a t ; t+x}^{A} * E_{t}\left(P_{F l o a t ; t, t+x}^{A}\right) . \\
& E_{t}\left(N C F_{t+x}\right)=\sum Q_{F i x ; t+x}^{L} * P_{F i x ; t+x}^{L}+\sum Q_{\text {Float } ;+x}^{L} * E_{t}\left(P_{\text {Float } ; t, t+x}^{L}\right) .
\end{aligned}
$$

The hedger expects the future prices relevant for the expected quantities to be at the level of the currently traded forward contracts. If these are not available, then she expects 
them at a level that does not enable financial or physical carry arbitrage (where impossible to determine, the cost of carry $c c_{t, t+x}$ is expected to be 0 ):

$$
E_{t}\left(P_{\text {Float } ; t, t+x}\right)=\left(1+c c_{t, t+x}\right) * P_{t} .
$$

As a subject motivated by profit, the hedger naturally tries to maximise the expected discounted profit $\pi_{t}$ denominated in the domestic currency (the superscript $F$ signifies that the variable is denominated in terms of the foreign currency, the superscript $D$ signifies that the variable is denominated in terms of the domestic currency):

$$
\pi_{t}=\sum_{x=0}^{\infty} \frac{E_{t}\left(E R_{t+x}\right) *\left[E_{t}\left(P C F_{t+x}\right)^{F}-E_{t}\left(N C F_{t+x}\right)^{F}\right]+\left[E_{t}\left(P C F_{t+x}\right)^{D}-E_{t}\left(N C F_{t+x}\right)^{D}\right]}{1+I R_{t+x}^{D}}
$$

where the hedger makes expectations on the future exchange rate $E_{t}\left(E R_{t+x}\right)$ in accordance with the covered interest rate parity at the level of forward rate quotations ${ }^{2}$ :

$$
E_{t}\left(E R_{t+x}\right)=E R_{t} * \frac{1+I R_{t+x}^{D}}{1+I R_{t+x}^{F}}
$$

From the above equation, it is clear that the hedger's profit depends on the expected exchange rate $E_{t}\left(E R_{t+x}\right)$ and $P_{\text {Float }}$ : if the foreign currency appreciates in relation to the domestic currency, this translates into a positive impact on $\pi_{t}$ through expected positive cash flows and a negative impact on $\pi_{t}$ through expected negative cash flows. Because the float part of the expected cash flows has not been concluded yet with any third party, it is still possible to adjust the quantities $Q_{\text {Float }}$ on both the assets and the liabilities sides: the hedger will try to create more assets denominated in the foreign currency $\left(Q_{\text {Float }}^{A}\right.$ is a positive function of the current exchange rate) and to create fewer liabilities in the foreign currency ( $Q_{\text {Float }}^{L}$ is a negative function of the current exchange rate). The opposite applies to foreign currency depreciation: the hedger will try to create more foreign currency liabilities and fewer foreign currency assets (for example, by decreasing the volume of intended exports that has not been contracted until a time of weakening of the foreign currency).

The hedger's profit also depends on the $P_{\text {Float }}$ assets and liabilities prices: if the foreign prices increase (still denominated in the foreign currency), the hedger will try to increase the quantities of her foreign assets $\left(Q_{\text {Float }}^{A}\right.$ is a positive function of $\left.P_{\text {Float }}^{A}\right)$ and lower the quantities of her foreign liabilities $\left(Q_{\text {Float }}^{L}\right.$ is a negative function of $\left.P_{\text {Float }}^{L}\right)$.

$$
\begin{gathered}
Q_{\text {Float }}^{A}=Q_{\text {Float }}^{A}\left(E R_{t ;[+]}, P_{\text {Float } ;[+]}^{A}\right) . \\
Q_{F} \text { loat }^{L}=Q_{F} \text { loat }^{L}\left(? \text { ER }_{(t ;[-])}, P_{(\text {Float } ;[-])}^{L}\right) .
\end{gathered}
$$

2 In fact, equation (6) applied to equation (5) only states that the hedger discounts the expected positive and negative cash flows denominated in the foreign currency by the foreign interest rates and recalculates these discounted flows into the domestic currency by the current Exchange rate $E_{t}$ while the domestic flows are still discounted by the domestic relevant interest rates. 
As described, for example, by Čadek; Rottová \& Saxa [2011] a considerable portion of FX hedgers attempt to apply natural hedging to a significant extent: in case the hedger sees her long FX exposure increase, she tends to increase her foreign currencydenominated liabilities $\left(Q_{\text {Float }}^{L}\right.$ would thus be a positive function of $\left.C F_{t}\right)$. This paper will abstract from the possibility of exposures being naturally hedged. Nevertheless, it has to be mentioned that natural hedging in general diminishes the impact of hedger behaviour on order flow under circumstances described in Section 1.2. The possibility of exposures being naturally hedged is not included, because it would decrease the clarity of the model while improving its ability to explain by only a relatively small margin. We can simply assume that allowing for natural hedging decreases the effects of hedgers' behaviour on exchange rates. It is the author's opinion that this applies especially to gradual, slow moves in the "trigger" prices, because during dramatic moves (which lie at the centre of the empirical part of this paper), the hedger is more likely to prefer forward or spot contracts, as these are more suitable for swift action.

While minimising the FX market risk exposure, the hedger needs to remember to secure her main business activity cash needs. For this reason, she always keeps $C F_{t, z}$ above the level of $C F_{m i n}$, on which she decides based on her risk preferences $R$, volatility of liquidity needs $L$ and exchange rate volatility $\sigma$ (where $C F_{\min }$ is a positive function of all of the mentioned parameters):

$$
\begin{gathered}
\left.C F_{t, z}=\sum \frac{E_{t}\left(P C F_{t+x}\right) E_{t}\left(N C F_{t+x}\right)}{I R_{t x}} ; z \epsilon<0 ; \infty\right), \\
C F_{t, z} \geq C F_{\text {min }} \\
\left.C F_{\text {min }}=C F_{\text {min }}\left(R_{[+]}, L_{[+]}, \sigma_{[+]}\right) ; z \epsilon<0 ; \infty\right) .
\end{gathered}
$$

Because dealing with hedging instruments carries certain costs (time, possibility of over-hedging and correction in the following term, etc.), $C F_{t}$ is not always kept at the level that ensures both the necessary liquidity and minimal exposure at once, but in case the exposure gets too high, the hedger will certainly step in and decrease her exposure. For the purposes of this paper, let us imagine that the hedger does not allow for her exposure $C F_{t}$ to exceed a certain threshold amount $T$ :

$$
C F_{t} \leq C F_{\min }+T \text {. }
$$

The hedger will tend to decrease the volatility of her profit and loss coming out of FX market risk by decreasing the volume of her exposure to the foreign currency exchange rate volatility $\sigma$ : the threshold amount determining the maximum acceptable exposure is a negative function of the relevant exchange rate volatility:

$$
T=T\left(\sigma_{[-]}\right) \text {. }
$$

Equations (10) and (12) represent conditions that have to be fulfilled for liquidity and hedging purposes while the hedger maximises the expected discounted profit $\pi_{t}$. 
It is assumed that the exchange rate $E R_{t}$, foreign forward and current prices $P$ and foreign and domestic forward and current interest rates $I R$ are exogenous to the model. Apart from natural hedging (managing $Q_{\text {Float }}$ on the assets and liabilities sides based on predicted exposure), it is assumed that the hedger uses only deliverable and non-deliverable forward and spot contracts for FX hedging purposes. This assumption should not pose a very serious threat to the model validity as most of the other hedging instruments are either created out of the basic ones (such as currency spreads) or at least have a relatively similar nature regarding the creation of order flow and hedgers' behaviour during shocks (for example, FX options).

A significant part of the assumptions on hedger behaviour is similar to the assumptions that Carlson \& Osler [1996] apply to their "liquidity trader"/“Current Account Trader": both the hedger in this paper and Carlson and Osler's liquidity traders are interested in their main business activity, are trying to avoid speculation (risk) originating from side business activity and (as most of the economic entities modelled) both are assumed to maximise their expected profits, while the exchange rate enters their decisions on the volumes exported/imported. Here the similarities end, as Carlson and Osler are more interested in rational speculator behaviour and do not dig as deep into the foundations of how the hedger's (liquidity trader's) risk exposure is created and managed.

Most of the past research focused on speculators (entities taking action on the market based on their expectations of the future rate levels). Forming expectation about foreign exchange is absolutely beyond the scope of this paper, because the behaviour of speculators and hedgers is driven by different motivations. It needs to be said that hedgers' operations can explain only part $^{3}$ of exchange rate development, but also that the traditional models (based on expectations) do not score good results, which means that right now we are not able to predict speculators' part in rate creation, but the hedgers' motivation analysis can shed some light on some defined periods (for example periods with extreme moves in prices of other assets, rebounds in exchange rates, etc.).

\subsection{Impact of hedger behaviour on order flow with implications for exchange rate development}

It was mentioned in the Introduction that order flow is regarded as a vessel for carrying new information to the market. Section 1.1 has specified the hedger's motivation to decrease her FX exposure based on the assumption that the hedger does not have timely access (or it would be too costly for her) to gain the information necessary to be persistently profitable on the FX market, which is seemingly in direct contrast to the statement from the Introduction. The hedger (by being active on the FX market) brings the information on the stock (or more precisely the excess or deficit of the stock) of the currency held by non-resident entities (from the currency residency point of view).

3 Measuring the contribution to rate creation and even mere distinguishing between speculators and hedgers as they are regarded in this paper is extremely difficult because the difference does not lie in the entity's institutional type (investment bank/pension fund/car exporter/etc.), but in the motivation of holding, creating or disposing of the FX market risk - one entity can play both roles in different situations. An aggressive investment fund can hedge its FX exposure at first, but later decide to hold on its gradually created long or short position in foreign currency based on newly created expectations. 
If, for example, an FX dealer notices in the morning that a large USD position is being accumulated by European-based clients involved on the coal markets that are usually not very active on the foreign exchange market, he might expect this pattern to keep occurring throughout the day and would then be more inclined to long dollar than usually. The market might also notice a large position being built up by certain types of entities and might try to use this information (which was not available to the market prior to the client's order flow creation) while the position is being built or when the entities are most likely to be pushed to decrease the accumulated position.

In case we accept the hypothesis that the stock of the currency held by non-residents does not affect the expected or current level of the exchange rate of the currency, then the order flow created by the hedger based solely on the motivation to manage the stock should have no predictive power for the exchange rate. In this case, even if the created order flow manages for a short period of time to move the exchange rate away from the level expected by the speculators, then the subjects with better (or more relevant) information should generally be able to return the exchange rate to the level where it was prior to the hedger's intervention (provided that the expectations did not change).

This section will take a look at three types of exogenous shocks to which the hedger will react:

1. An increase in the price of potential assets denominated in the foreign currency $P_{\text {Float }}^{A}$;

2. An increase in the price of potential liabilities denominated in the foreign currency $P_{\text {Float }}^{L}$;

3. An increase in the current exchange rate $E R_{t}$ (appreciation of the foreign currency in relation to the domestic currency).

In the first case, the hedger's expected positive cash flow $P C F$ increases through two different channels. In the first channel, $P C F$ rises simply because of the increase in $P_{\text {Float }}^{4}$. In the second channel, the positive cash flow $P C F$ also climbs, but this time because of the increase in the potential asset quantity denominated in the foreign currency $Q_{\text {Float }}^{A} . Q_{\text {Float }}^{A}$ rises because the hedger will try to allocate a bigger part of her main business activity in the foreign country due to relatively higher prices (and thus higher expected profit). As a result of the increasing positive cash flow $P C F$, the whole cash flow $C F_{t}$ rises, which can potentially create a breach of the threshold $\mathrm{CF}_{\min }+T$. Once the threshold is breached, the hedger is forced to eliminate the excessive exposure. She can do this via spot or forward FX contracts or by increasing foreign currency liabilities connected to her main business activity (natural hedging). While natural hedging would have no immediate direct impact on order flow, hedging through spot/forward contracts would have a negative impact on order flow: the hedger would create foreign currency sell-side orders, which would decrease order flow. This shift in order flow should then create depreciating pressure on the exchange rate of the foreign currency.

An increase in prices of assets denominated in the foreign currency held by domestic currency residents has a depreciating impact on foreign currency as the result of domestic hedger entities' behaviour. This result is in accordance with Hau \& Rey [2006, pp. 307], who "derive a negative correlation between foreign equity excess returns (in local currency) and the corresponding exchange rate returns". For example, 
if the German price level increases dramatically ceteris paribus, Czech exporting entities will be more motivated to increase exports to Germany and hedge the expected increased foreign currency cash inflow by selling EUR for FX hedging purposes (this may happen even before the export is really contracted, if the expectation of increased exports is strong).

In the second case, the impact on order flow is different for each of the channels mentioned above. As a result of the increase in $P_{\text {Float }}^{L}$, the negative cash flow NCF increases. This lowers the overall expected cash flow exposure $C F_{t}$ and creates the possibility that at the time $t+z$ the expected level of liquidity $C F_{t+z}$ will fall below the minimal required liquidity level $C F_{\text {min }}$. When $C F_{t+z}$ falls below $C F_{\min }$, the hedger needs to buy foreign currency in order to secure her necessary foreign currency liquidity, which creates positive order flow in the foreign currency. In the second channel, the hedger will attempt to decrease the potential quantity of her liabilities denominated in the foreign currency $Q_{\text {Float }}^{L}$ in order to diminish the negative impact of the price hike on her expected profit $\pi_{t}$. This affects expected negative cash flow NCF in a negative manner. Lower $N C F$ means higher exposure to the foreign currency. This means the hedger will have tendencies to decrease her exposure by selling the foreign currency, which creates negative order flow in the foreign currency.

Because the effects of the hedgers' behaviour on order flow are different in the two transmission channels presented, it is not certain how the order flow will move in response. The result depends, to a large extent, on the hedger's ability to limit her potential liabilities quantity denominated in foreign currency $Q_{\text {Float }}^{L}$, which is driven by the elasticity of the hedger's demand for the underlying product. Where there is very low elasticity, the price channel will get an upper hand, resulting in positive order flow and thus an appreciating pressure on the foreign currency. This being said, the hedger's behaviour should have a lower impact on the exchange rate under a shock into the liabilities-side prices than under a shock into the asset-side prices presented above.

In the third case, the impact on order flow is channelled by both positive and negative expected cash flows $P C F$ and $N C F$. The hedger reacts to the appreciation of the foreign currency by trying to increase the positive expected cash flow $P C F$. This is done by increasing the potential asset quantity denominated in the foreign currency $Q_{\text {Float }}^{A}$. Exactly the opposite can be said about $N C F$ and $Q_{\text {Float }}^{L}$. Both of these responses tend to increase the hedger's expected profit exposure to the volatility of the foreign exchange rate. Because of this, the hedger will enter into forward or spot contracts selling the foreign currency, creating negative order flow, which in turn presses on the foreign currency's depreciation.

Shock 2 should have the mildest effect on order flow and thus on the exchange rate compared to the other two shocks. This is because both channels of responses to shocks 1 and 3 impact the order flow in the same direction. The hedgers in aggregate (in sum for both domestic and foreign-currency residency) likely have lower net exposure than the exposure that the hedgers have from one asset class only: for example, it could be expected that for EUR-based entities, a higher exposure is created on USD financial assets than that created by USD-based entities on EUR-denominated financial assets, given the nature of both the markets (the American stock market is much more mature and liquid than the German one, for example). This would mean that the net sum of EUR- and USD-based hedger entities' exposure on stock markets is relatively large. 
On the other hand, in case US and EU hedgers aim for similar exposures and there is a similar number of them, then the overall hedger exposure between EUR and USD would be close to zero. In addition to this, it is likely that hedgers will react much more swiftly to shocks in prices of assets and liabilities with which they are more familiar, rather than to shocks in the exchange rate, about which they usually do not have precise information (or at least they do not possess the ability to process the information in short enough time). For these reasons, shock 1 should have a bigger impact caused by hedgers on the exchange rate than shock 3 .

\subsection{Empirical model: data used}

The hypotheses reached in Section 1.2 based on the analysis of the hedger's behaviour are tested on real data in Chapter 2. The empirical analysis was performed by applying the fuzzy clustering algorithm developed by the author and inspired by Giles \& Draeseke [2001], as further explained in Section 1.4. For each time series of the impulse (or shock) variable (Brent Oil spot prices, Standard \& Poor's 500, Dow Jones Industrial Average, EURCZK, EURUSD, USDCAD and USDJPY exchange rates ${ }^{4}$ ), the biggest $5 \%$ of shocks (measured by close-of-business-day logarithmic returns) during the time period between 1 January 2010 and 31 May 2015 were chosen together with the corresponding 5 subsequent close-of-business-day logarithmic returns of the relevant exchange rate (when the impulse variable is the exchange rate itself, the first measured logarithmic return of the exchange rate was the one following the initial shock; in the rest of the cases, the first exchange rate $\log$ return is measured between the closing rate on the day when the shock occurred). Only the biggest 5\% shocks were chosen in order to recognise the most pronounced patterns more easily. Only business days are taken into account. Out of these biggest shocks, the positive and negative shocks were analysed separately, because it was expected that the behaviour of market participants (and thus also the observed patterns in the exchange rates) may be asymmetric in this regard.

\subsection{Empirical model description}

The logarithmic exchange rate returns following the selected shocks were split into three clusters: primary, secondary and tertiary with the following logic behind these groups:

- inside the primary cluster, the speculators are still active and exchanging the currencies based on expectations changed by incorporating the observed shock;

- in the secondary cluster, the hedgers are very active, aggressing orders to hedge their newly created exposure;

- nothing specific is expected of the tertiary cluster except that the hedging entities have already left the market.

4 Data sources: Brent Oil spot prices, Standard \& Poor's 500, Dow Jones Industrial Average: http://research.stlouisfed.org/fred2/series. EURCZK, EURUSD: https://www.ecb.europa.eu/stats/ exchange/eurofxref; USDCAD, USDJPY: http://www.federalreserve.gov/releases/h10/hist/. 
Clustering of the ER returns was performed as follows: each ER log return was set into a two-dimensional space with one dimension being the rank of the period after the period in which the initial shock was observed (values 1 to 5) and the second dimension being the signum of the multiple of the ER log return and the initial shock (also in the form of either negative or positive logarithmic return) (values -1.0 or 1). The coordinates in the first dimension of the initial centroids were set to 1.3 and 5 for the primary, secondary and tertiary clusters respectively.

The coordinates in the second dimension of the initial centroids were set to either 1 or -1 . Each model was run for all eight possible combinations of the second-dimension coordinates under the three clusters. The best model ${ }^{5}$ was then chosen as representative. The individual ER returns were then inserted into the cluster based on the minimum distance to one of the centroids.

An alternative clustering method was used to help confirm the validity of the approach, where the ER data were clustered into three dimensions (period, multiple of the rate return and the shock return, and absolute value of the rate return). In this method, the centroids were allowed to adjust for 10 repetitions: after all clusters were determined under each repetition, a new centre of each cluster was calculated by searching for the minimum sum of distances between new centroid and the clustered points. Although the centroids always adjusted gradually and became stable after a few repetitions, the results of the whole model were very sensitive to the cluster initiation under the alternative clustering method. Very similar conclusions on either the negative or the positive impact of hedgers (inside the secondary cluster) on the exchange rate were reached no matter which of the two mentioned approaches was used. The presentation of the results in this paper will follow only the first-described two-dimensional approach to clustering.

A membership function (the function assigning to each period rank the measure to which the ER log return is likely to fall into each of the clusters) was estimated based on historical data by taking the weights of each cluster inside the relevant period (in the presented graphs, the membership function is always the upper one). For each of the clusters, an ordinary least-squares regression with a single parameter (the level parameters were statistically insignificant in all cases) was run to determine the dependency of the clustered logarithmic gains on the initial shock (the daily logarithmic gain/loss in the initial shock period). In case the dependency parameter was statistically insignificant, it was set to zero. The following impulse-response function $I$ with elements $j=1$ to 5 was calculated:

$$
I_{j}=\sum_{i=1}^{3}\left(m_{i, j} * p_{i, j} / \sum_{j=1}^{5} m_{i, j}\right) ; i=1,2,3 ; j=1,2,3,4,5
$$

where the indexes $i$ define to which cluster the element is assigned (indexes 1, 2 and 3 are assigned to the primary, secondary and tertiary clusters respectively) and the indexes $j$ ( 1 to 5 ) define to which period the element is assigned. In addition, $m_{i, j}$ is an element of the membership function matrix $(3 \times 5), p_{i}$ is an element of the parameter matrix $(3 \times 1)$ obtained from the OLS regressions.

5 Measured by the index $\alpha-$ see equation (15). 
The obtained impulse-response function $I$ can then be used to estimate the response of the exchange rate logarithmic return for each period to the respective initial shocks in the impulse variable. The quality of the estimation was then measured by the $\alpha$ [\%] index of variability of the exchange rate logarithmic returns explained by the fuzzy clustering model, versus the full variability of the exchange rate logarithmic returns (random walk model):

$$
\alpha=1-\sum_{x=1}^{n}\left[\sum_{j=1}^{5}\left(\text { Impulse }_{x} * I_{j}-\text { ERlogReturn }_{x, j}\right)^{2}\right] / \sum_{x=1}^{n} \sum_{j=1}^{5}\left(\text { ERlogReturn }_{x, j}\right)^{2} .
$$

Only models with a positive $\alpha$ were taken into account. In case no model could deliver better than the random walk results, the given impulse-response relationship was concluded as non-existent (marked " $\mathrm{nE}$ " in Table 1 in the following Chapter).

\section{Results: Model verification and discussion}

Section 1.3 has established several expected results of the model:

Firstly, an increase in the price of potential assets denominated in the foreign currency $P_{\text {Float }}^{A}$ should lead to a depreciation of the foreign currency, which is USD in all the analysed cases (the secondary cluster parameter should be positive for EURUSD; it should be negative for USDJPY and USDCAD). Dow Jones Industrial Average (DJIA) and Standard \& Poor's 500 (S\&P 500) index values ${ }^{6}$ were chosen to represent the side of potential assets as defined in Section 1.1. In case the value of the index denominated in the foreign currency (USD) increases, the domestic (EUR/CAD/JPY) investors and exporters receive (via margins) or expect to receive (when selling the shares or the commodity) a positive cash flow, which increases their long exposure in USD and, according to the model, should create a pressure on them to decrease the long-dollar exposure. The analysis performed on oil prices and DJIA and S\&P 500 indexes suggests the opposite to the expectations formed in Section 1.2: the parameter assigned to the secondary cluster (representing the hedger activity) was negative for impacts of both DJIA and S\&P 500 shocks on EURUSD and it was positive for USDCAD. The impact of DJIA and especially S\&P 500 on USDJPY had the expected result in the secondary cluster, but the models were not very successful in terms of $\alpha$.

The figures below show a summary of the model results for chosen impact variables and response exchange rates. The graphs are divided into positive and negative shockimpact relations. The upper figures show the estimated membership functions for the described clusters. The lower figures show the comparison of the averaged logarithmic gains/losses in the relevant exchange rates over five successive periods after the shocks and the logarithmic returns in the ER that are estimated by the model. P, S and T mark the above-described OLS regression parameters of the ER logs clustered into the primary, secondary and tertiary clusters respectively.

6 Together with Brent Oil prices, specifically for USDCAD (because Canada is an oil exporter). 
Figure 1, Figure 2 | Impact of $P_{\text {Float }}^{A}$ shock (DJIA, S\&P 500) on EURUSD and USDCAD

DJIA shock impact on EURUSD future returns, $\mathrm{S}>0$ expected
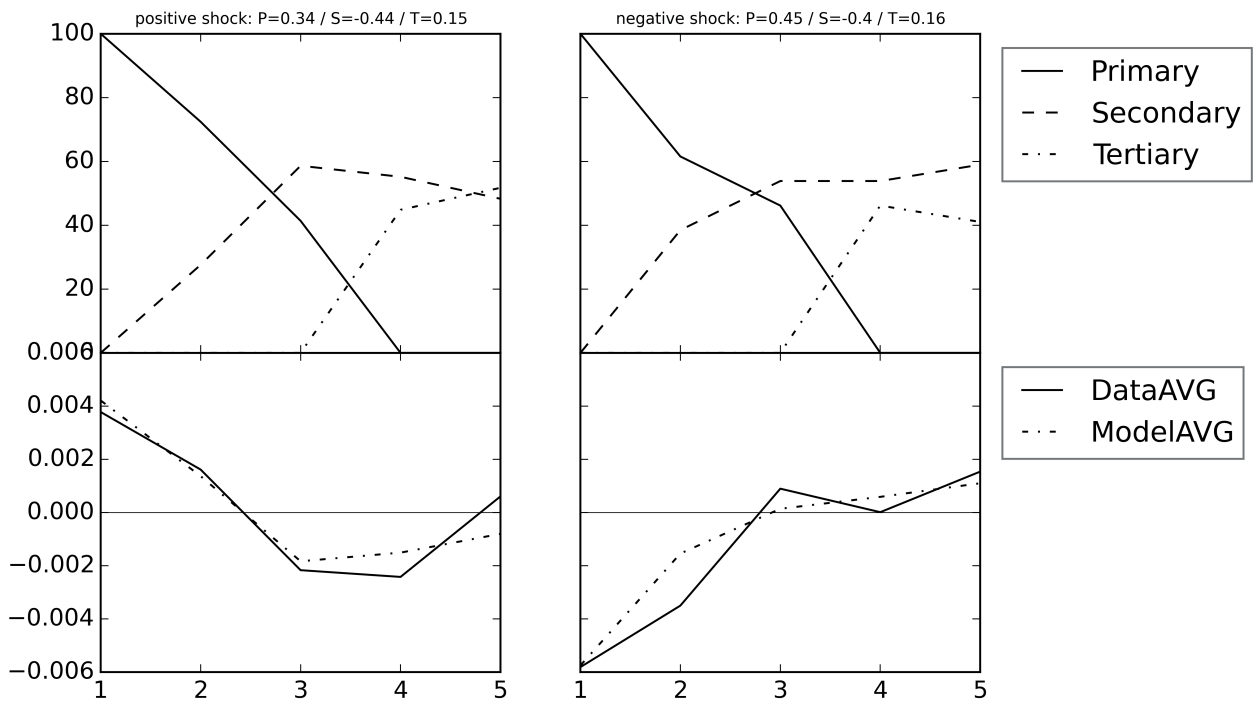

S\&P 500 shock impact on USDCAD future returns, $\mathrm{S}<0$ expected
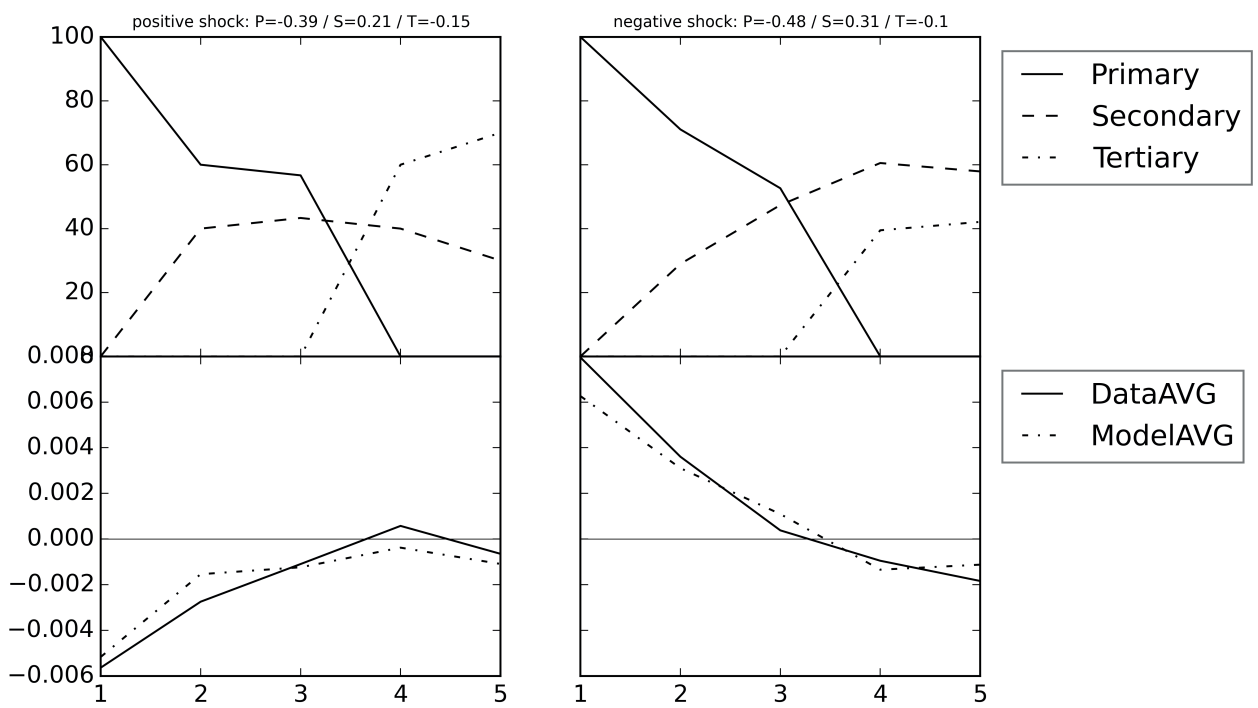

Source: author's computation 
There are several reasons that might explain why the hypotheses linked to $P_{\text {Float }}^{A}$ shock were not confirmed. First of all, it is possible that due to the empirical model specification, the hedging actions fall into the primary instead of the secondary cluster: the primary cluster does have the expected sign most of the time for $P_{\text {Float }}^{A}$ shocks. Further research is certainly necessary to analyse the patterns in exchange rate movements following asset/ commodity shocks on high-frequency data in more depth (for example, Ferraro; Rogoff \& Rossi [2011] conclude that oil prices do have predictive power for the EURCAD rate in the short term, while in the longer terms such as at monthly or quarterly frequencies, the link is not observable). It would also be beneficial to better assess what lag should be expected before the hedging entities act. There are also many factors weighing in during the exchange rate creation, especially in the short term. Two of the largest stock indexes in the world were chosen to represent the shock variable, which also mirror to a great extent the expectations on the United States' economic health. As such, the biggest moves in these indexes trigger very complex behaviour of subjects inside and outside USD residency. This behaviour may be linked to exchange rate creation in many different ways: for example, conservative investors moving capital inside/outside an economy based on positive/negative significant news that is expected to have long-term impact. Another possible explanation is that there is a lower level of hedging involved in connection with shocks to prices of financial assets, because subjects that operate on stock markets may be less motivated to hedge their exposures due to benefiting from international diversification of the market risk of their portfolio (as shown, for example, in Solnik [1974]). This would weaken the impact of hedgers as being analysed in the empirical model presented. The existence of a relation (and its direction and positive/negative effect) between stock prices and exchange rates has been researched by many authors, but the results are thus far inconclusive as presented, for example, by Tabak [2006] in his extensive literature review on this matter.

On the other hand, the model on the $P_{\text {Float }}^{L}$ shock, which is represented in the analysis by a shock in Brent Oil prices, was able to provide positive results for EURUSD. This is because the demand for oil is quite inelastic; an increase in oil prices was expected to lead hedging entities to hedge their increasing foreign-currency (USD) outflows by purchasing the mentioned foreign currency. Therefore, oil price hikes should have the tendency to appreciate the dollar while the hedgers are active. The empirical analysis suggests that this might be the case with EURUSD. The model for USDJPY did not show very strong results as it was able to score a positive $\alpha$ only for the negative impact on oil prices, while the sign for the secondary-cluster OLS regression parameter was other than expected. 
Figure 3, Figure 4 | Impact of $\mathrm{PL}_{\text {Float }}$ shock (Brent Oil spot) on EURUSD and USDJPY (positive shock unsuccessful)

Brent Oil spot price shock impact on EURUSD future returns, $\mathrm{S}<0$ expected
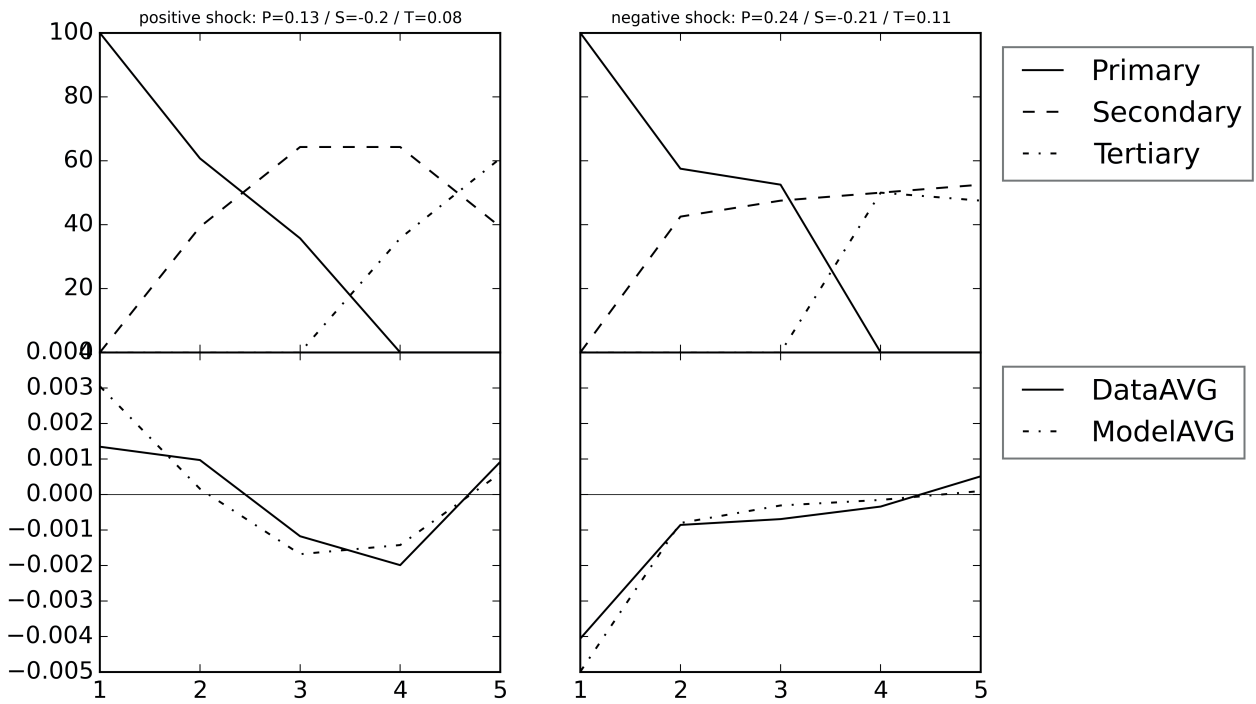

Brent Oil spot price shock impact on USDJPY future returns, $\mathrm{S}>0$ expected
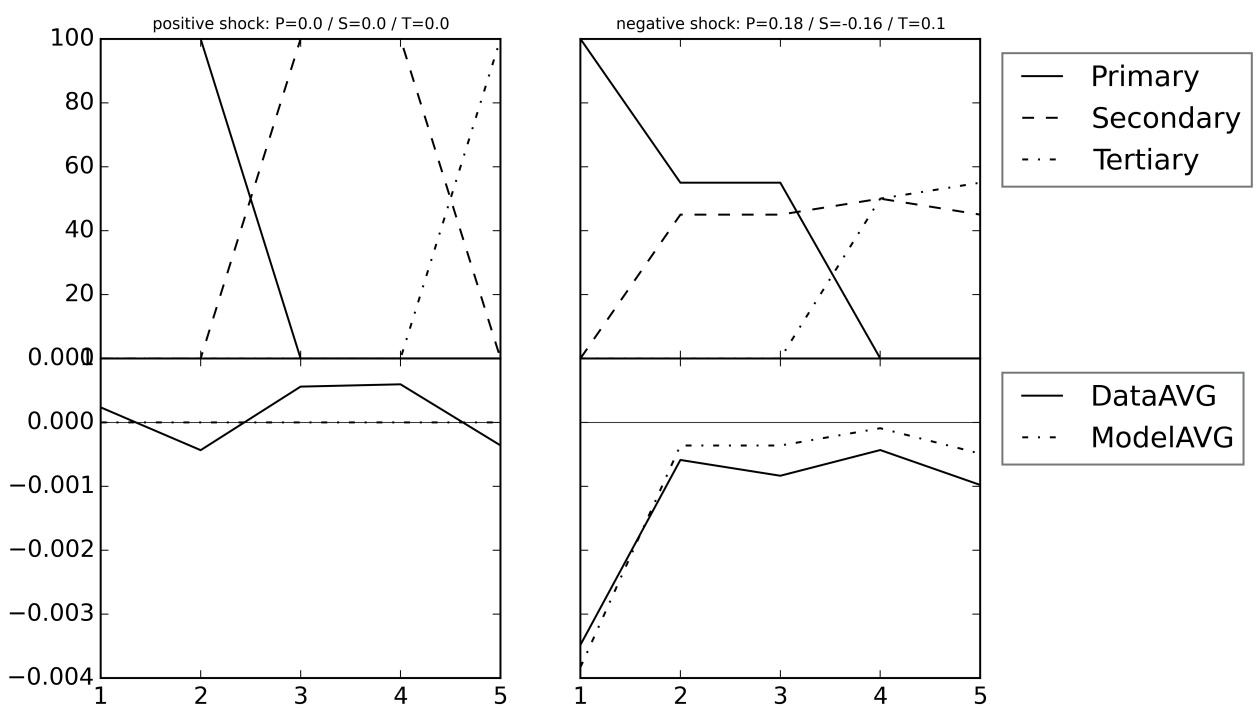

Source: author's computation 
Figure 5, Figure 6 | Impact of ER shock on EURUSD (unsuccessful) and EURCZK

EURUSD price shock impact on EURUSD future returns, $S<0$ expected
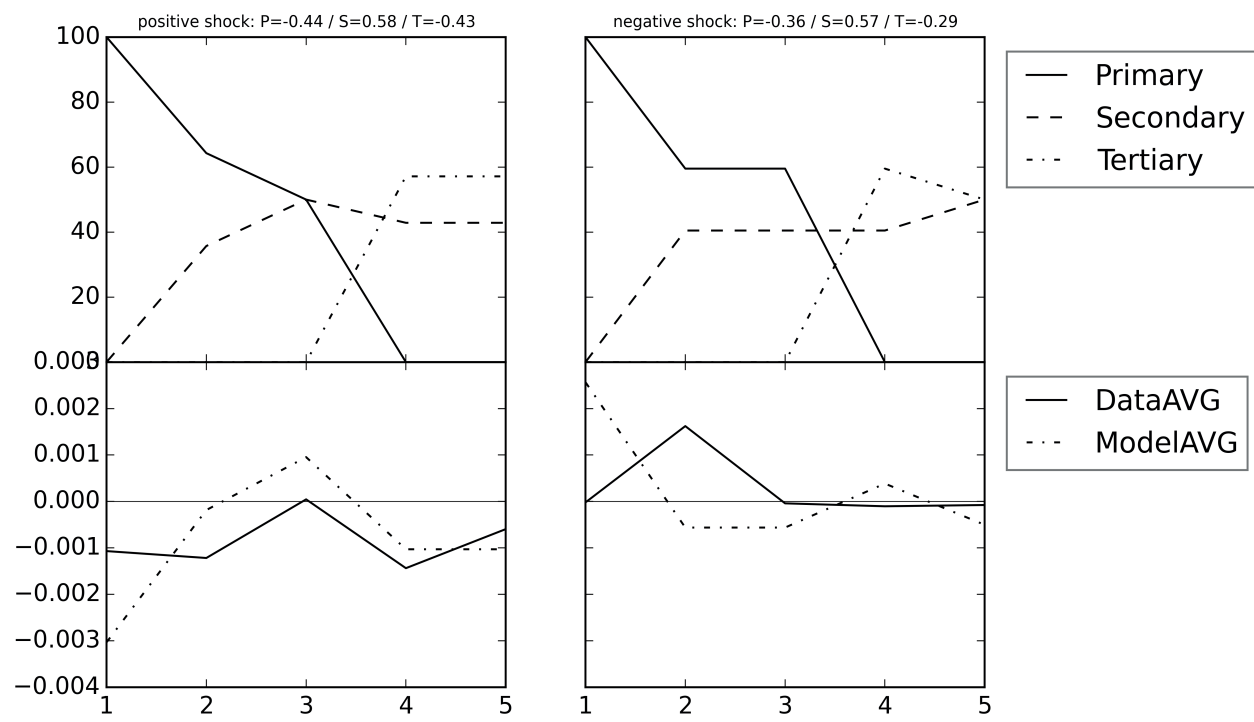

EURCZK price shock impact on EURCZK future returns, $\mathrm{S}<0$ expected
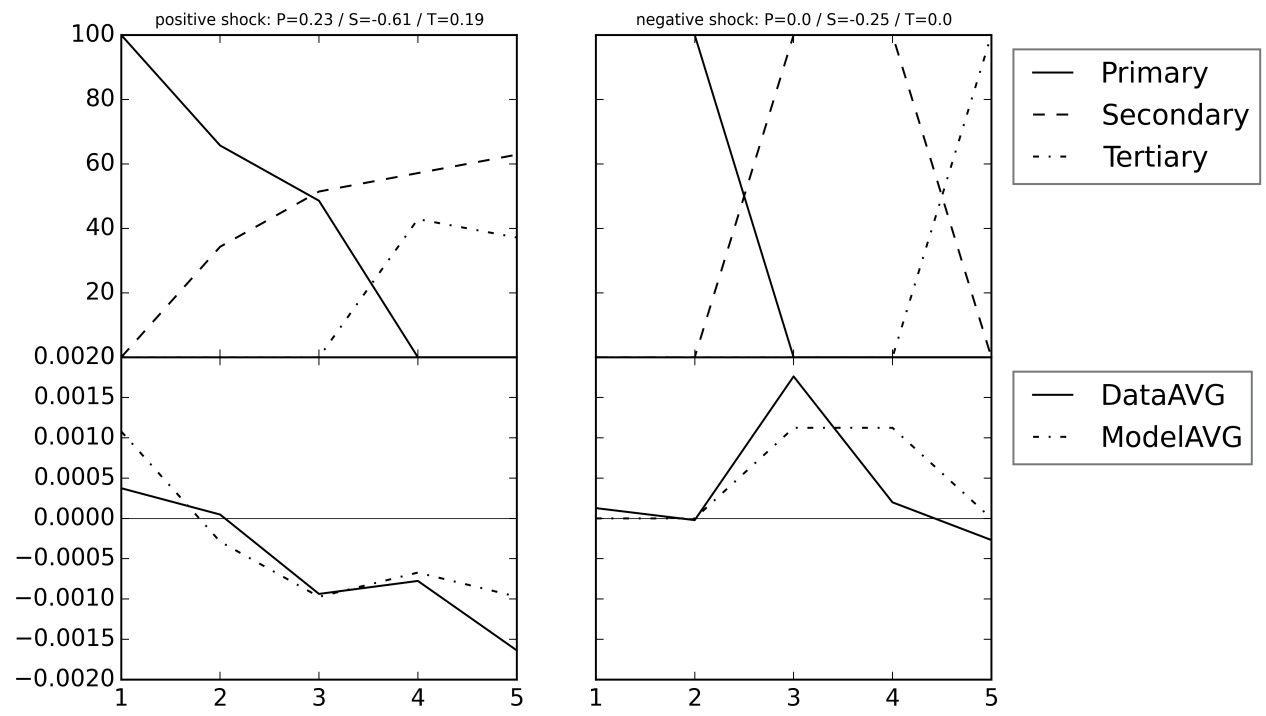

Source: author's computation 
Partially positive outcome was also yielded from the analysis of the third shock: in the exchange rate itself. The expected effect of hedgers was found for EURCZK (with a low $\alpha$ score), but no stable pattern of ER returns following big shock in the rate itself was found in the data for EURUSD, USDJPY, and USDCAD. The reason for this may be a very high level of speculation on the liquid foreign exchange pairs, which might be covering the hedgers' actions more consistently than for EURCZK. Building on findings of Eom; Hahn \& Joo [2003], who were able to observe significant autocorrelation for the exchange rate of the Korean won to USD prior to won liberalisation, but not afterwards, it could be derived that because EURUSD, USDJPY and USDCAD are extremely liquid and effective relative to EURCZK, these rates will have lower tendencies to form patterns upon themselves. Autocorrelation in exchange rates is also not found in the data by Hsieh [1988]. Another explanation might be the fact that the USA, Canada and the Eurozone are big and quite closed economies, whereas the Czech Republic is a small and open one, which means that the ratio of entities trading the currency pair because of their needs in their main business activity to all entities present on the market will be higher.

Lastly, it was expected that if the hedgers do bring previously unknown information to the market, the market should not have tendencies to reverse the hedgers' actions. Translated into the empirical model, if this thesis is right, the OLS parameters for the tertiary cluster would be statistically insignificant. The analysis has shown that although the estimates of the tertiary parameters were smaller than those of the secondary ones, they were in most cases statistically different from 0 and had the inverse sign. This may indicate that (because the market does not fully dispose of the effects that the hedgers have brought) the hedgers do bring new, previously unknown information to the market, but the rest of the market does not find a significant part of it relevant for price creation.

The following table wraps up the main resulting information gained from the models:

Table 1 | Overview of empirical analysis results, "I" splits positive and negative impact-related data respectively

\begin{tabular}{|c|c|c|c|c|c|c|}
\hline \multirow{2}{*}{$\begin{array}{l}\text { shock } \\
\text { class }\end{array}$} & \multirow{2}{*}{$\begin{array}{c}\text { shock } \\
\text { variable }\end{array}$} & \multirow{2}{*}{$\begin{array}{c}\text { response } \\
\text { ER }\end{array}$} & \multirow{2}{*}{$\begin{array}{l}\text { best } \\
\alpha[\%]\end{array}$} & \multicolumn{2}{|c|}{ Secondary cluster OLS parameter } & \multirow{2}{*}{$\begin{array}{c}\text { Tertiary cluster } \\
\text { OLS parameter } \\
\text { sign }\end{array}$} \\
\hline & & & & expected sign & modelled sign & \\
\hline $\mathrm{P}_{\text {Float }}^{\mathrm{A}}$ & DJIA & EURUSD & $11 / 8$ & positive & negative / negative & $0.15 / 0.16$ \\
\hline $\mathrm{P}_{\text {Float }}^{\mathrm{A}_{\mathrm{F}}}$ & DJIA & USDJPY & $2 / 2$ & negative & positive / negative & $-0.14 / 0.15$ \\
\hline$P_{\text {Float }}^{A_{1}}$ & DJIA & USDCAD & $20 / 21$ & negative & positive / positive & $-0.17 /-0.11$ \\
\hline $\mathrm{P}_{\text {Float }}^{\mathrm{A}}$ & S\&P 500 & EURUSD & $7 / 9$ & positive & negative / 0 & $0.16 / 0.00$ \\
\hline $\mathrm{P}^{\mathrm{A}}{ }_{\text {Float }}$ & S\&P 500 & USDJPY & $1 / 2$ & negative & negative / negative & $0.09 / 0.12$ \\
\hline$P^{A}{ }_{\text {Float }}$ & S\&P 500 & USDCAD & 17 / 21 & negative & positive / positive & $-0.15 /-0.10$ \\
\hline $\mathrm{PA}_{\text {Float }}$ & Brent Oil & USDCAD & $19 / 16$ & negative & positive / positive & $-0.10 /-0.08$ \\
\hline $\mathrm{PL}_{\text {Float }}$ & Brent Oil & EURUSD & $2 / 7$ & negative & negative / negative & $0.08 / 0.11$ \\
\hline $\mathrm{P}_{\text {Float }}$ & Brent Oil & USDJPY & $\mathrm{nE} / 5$ & positive & $\mathrm{nE} /$ negative & $\mathrm{nE} / 0.10$ \\
\hline ER & EURUSD & EURUSD & $\mathrm{nE} / \mathrm{nE}$ & negative & $\mathrm{nE} / \mathrm{nE}$ & $\mathrm{nE} / \mathrm{nE}$ \\
\hline ER & USDJPY & USDJPY & $\mathrm{nE} / \mathrm{nE}$ & negative & $\mathrm{nE} / \mathrm{nE}$ & $\mathrm{nE} / \mathrm{nE}$ \\
\hline ER & USDCAD & USDCAD & $\mathrm{nE} / \mathrm{nE}$ & negative & $\mathrm{nE} / \mathrm{nE}$ & $\mathrm{nE} / \mathrm{nE}$ \\
\hline ER & EURCZK & EURCZK & $1 / 3$ & negative & negative / negative & $0.19 / 0.00$ \\
\hline
\end{tabular}

Source: author's computations 
Overall, the presented analysis offers mixed results in that there may be a significant link between the evolution of asset (financial assets, commodities) prices and exchange rates via behaviour of subjects acting as hedgers on foreign exchange markets. Because the variability of the exchange rates explained by the model (measured by $\alpha$ ) is significantly higher for USDCAD currency pair than for other analysed pairs, it is possible that the strength of this link depends to some extent on the similarity of the economies, although further research is necessary to confirm this.

\section{Conclusion}

The paper attempts to explain the motivation and mechanics behind foreign exchange hedger behaviour. Based on the presented model, several shocks were analysed and the impact on order flow and exchange rate was described together with some comparison of the extent of the impact. The hypotheses reached in the theoretical section were partially supported by the empirical analysis performed on the shock data: the pattern validation/ rejection algorithm based on the fuzzy clustering technique was used to check whether the hedgers indeed do have some impact on exchange rates. The pattern anticipated in the theoretical part of this paper for shocks in hedger asset prices was found for only one inspected combination out of seven, the possible explanation being a high level of speculation and a higher complexity of economic relations connected to these shocks. On the other hand, the empirical analysis of the shocks in Brent Oil prices for oil-importing countries and partially also in exchange rates themselves points to more optimistic conclusions: in case a persistent pattern was observed, its parameters were in most cases in accordance with the expectations on the parameters created in the theoretical part: a dramatic increase in Brent Oil prices tends to put appreciation pressures on the dollar against the currencies of oil-importing countries. Evidence of a pattern on the level of exchange rates shocks was found only for EURCZK (no persistent pattern was observed for EURUSD, USDCAD and USDJPY).

It is necessary to say that the validation method used was primarily designed to verify the hypotheses on signs of secondary-cluster OLS parameters. In order to use the findings for predictions, it would be necessary to fine-tune it more (especially the cluster centroid initiation). The weakness of the performed empirical analysis lies in its narrow scope: only seven shock variables and four exchange rate returns were looked into, which means the findings are not too robust and possibly not generally applicable even to impulse-response relation combinations where the original hypothesis formed in the theoretical part of this paper was not rejected on data. Because the traditional macroeconomic models fail in attempts to explain and predict exchange rates, the current trend in international finance is to base the research of foreign exchange markets increasingly on microeconomic foundations.

Although the empirical findings are convincing only to some degree, this paper presents that it may be possible to identify microstructure behavioural patterns of some types of market participants and draw conclusions on exchange rate evolution based on detailed analysis of such behaviour. The author also believes that it is necessary to first create stronger theoretical background for the microstructure approach to exchange rate research before moving to extensive data analysis. In short, we should first answer the question WHY and follow on to HOW only after we have at least a partial understanding of the main drivers behind short-term rate creation. 


\section{References}

CARLSON, J. and OSLER, C. L., 1996. Rational speculators and exchange rate volatility [Staff Paper 13]. Federal Reserve Bank of New York. [accessed June 30, 2015]. Available at: https://www.newyorkfed.org/medialibrary/media/research/staff_reports/sr13.pdf.

ČADEK, V.; ROTTOVÁ, H. and SAXA, B., 2011. Hedging Behaviour of Czech Exporting Firms [Working Paper Series 14]. The Working Paper Series of the Czech National Bank, Prague. ISSN 1803-7070. [accessed June 30, 2015]. Available at: https://www.cnb.cz/miranda2/ export/sites/www.cnb.cz/en/research/research_publications/cnb_wp/download/ cnbwp_2011_14.pdf.

EOM, K. S.; HAHN, S. and JOO, S., 2003. Partial Price Adjustment and Autocorrelation in Foreign Exchange Markets [typescript]. UC Berkeley. [accessed June 30, 2015]. Available at: http://faculty.haas.berkeley.edu/lyons/Eom\%20partial\%20price\%20adjustment.pdf.

ENGEL, CH. and WEST, K. D., 2005. Exchange Rates and Fundamentals. Journal of Political Economy. Issue 3, pp. 485-517. ISSN 1537-534X.

EVANS, M. D. D. and LYONS, R. K., 2002. Order flow and exchange-rate dynamics. Journal of Political Economy. Issue 1, pp. 170-180. ISSN 1537-534X.

FERRARO, D.; ROGOFF, K. S. and ROSSI, B., 2011. Can oil prices forecast exchange rates? [Working Paper No. 11-34]. Federal Reserve Bank of Philadelphia. [accessed June 30, 2015]. Available at: https://www.philadelphiafed.org/-/media/research-and-data/publications/ working-papers/2011/wp11-34.pdf.

GILES, D. E. A. and DRAESEKE, R., 2001. Econometric Modelling Based on Pattern Recognition via the Fuzzy c-Means Clustering Algorithm [Working Paper EWP0101]. University of Victoria, Department of Economics. ISSN 1485-6441. [accessed June 30, 2015]. Available at: http://www.uvic.ca/socialsciences/economics/assets/docs/econometrics/ewp0101.pdf.

HAU, H. and REY, H., 2006. Exchange Rates, Equity Prices, and Capital Flows. The Review of Financial Studies. Issue 1, pp. 273-317. ISSN 1465-7368.

HSIEH, D., 1988. The statistical properties of daily foreign exchange rates: 1974-1983. Journal of International Finance. Issue 1, pp. 129-145. ISSN 0022-1996.

RIME, D.; SARNO, L. and SOJLI, E., 2007. Exchange rate forecasting, order flow and macroeconomic information [Working Paper ANO 2007/2]. Norges Bank, Oslo. [accessed June 30, 2015]. Available at: http://www.norges-bank.no/Upload/60866/arb-2007-02.pdf.

SOLNIK, B. H., 1974. Why Not Diversify Internationally Rather Than Domestically? Financial Analyst Journal. Issue 4, pp. 48-54. ISSN 0015-198X.

TABAK, B. M., 2006. The Dynamic Relationship between Stock Prices and Exchange Rates: evidence for Brazil [Working Papers Series 124]. Central Bank of Brazil, Research Department. [accessed June 30, 2015]. Available at: https://www.bcb.gov.br/pec/wps/ingl/wps124.pdf. 